\title{
BMJ Global Health Regulating international clinical research: an ethical framework for policy-makers
}

\author{
Bernardo Aguilera (D) ,' David DeGrazia,, ${ }^{1,2}$ Annette Rid (i) ${ }^{1}$
}

To cite: Aguilera B, DeGrazia D, Rid A. Regulating international clinical research: an ethical framework for policymakers. BMJ Global Health 2020;5:e002287. doi:10.1136/ bmjgh-2020-002287

Handling editor Seye Abimbola

- Additional material is published online only. To view, please visit the journal online (http://dx.doi.org/10.1136/ bmjgh-2020-002287).

Received 2 January 2020 Revised 13 April 2020 Accepted 14 April 2020

Check for updates

(C) Author(s) (or their employer(s)) 2020. Re-use permitted under CC BY. Published by BMJ.

'Department of Bioethics, The Clinical Center, National Institutes of Health, Bethesda, Maryland, USA

${ }^{2}$ Department of Philosophy, George Washington University, Washington, DC, USA

Correspondence to Dr Annette Rid; annette.rid@nih.gov

\section{ABSTRACT}

The global distribution of clinical trials is shifting to low-income and middle-income countries (LMICs), and adequate regulations are essential for protecting the rights and interests of research participants in these countries. However, policy-makers in LMICs can face an ethical tradeoff: stringent regulatory protections for participants can lead researchers or sponsors to conduct their research elsewhere, potentially depriving the local population of the opportunity to benefit from international clinical research. In this paper, we propose a three-step ethical framework that helps policymakers to navigate this trade-off. We use a recent set of regulatory protections in Chile to illustrate the practical value of our proposed framework, providing original ethical analysis and previously unpublished data from Chile obtained through freedom of information requests.

\section{INTRODUCTION}

The global distribution of clinical trials is changing. Trials are shifting to low-income and middle-income countries (LMICs), where markets are expanding; participants are easily recruited; and research costs remain low. ${ }^{12}$ This shift has raised concerns about sponsors and researchers 'outsourcing' trials and possibly taking unfair advantage of vulnerable populations. ${ }^{3}$ For example, some researchers from high-income countries (HICs) have been criticised for using 'double standards' by conducting trials in LMICs that would not be ethically approvable in their home countries, such as placebo-controlled trials that withhold or delay the best proven treatments. ${ }^{45}$

In response, some LMICs have introduced stringent regulatory protections for clinical trial participants. For example, in 2012, India required that sponsors provide free clinical care to participants injured during a trial, whether or not the injury was researchrelated. ${ }^{6}$ However, stringent protections can lead sponsors to conduct their research elsewhere, depriving LMICs of the potential benefits of hosting studies. In India, for instance, clinical trial registrations fell sharply after the new protections were introduced. ${ }^{6}$

\section{Summary box}

- The global distribution of clinical trials is shifting to low-income and middle-income countries (LMICs), and adequate regulations are essential for protecting research participants.

- Policy-makers in LMICs often face an ethical trade-off: stringent regulatory protections can lead sponsors to conduct their research elsewhere, depriving LMICs of the potential benefits of international research.

- We develop a three-step ethical framework to guide policy-makers in dealing with key ethical considerations involved in navigating this trade-off.

- Using a recent set of regulatory protections in Chile, we illustrate the practical value of our proposed framework, providing original ethical analysis and previously unpublished data.

- The proposed ethical framework helps policymakers strike an appropriate balance between protecting research participants and reaping the benefits of appropriate clinical research.

At the time, the dominant reaction was negative: India might lose the benefits of international research. ${ }^{7}$ Indeed, international research is often regarded as an important means of improving infrastructure, training and enhancing economic activity in LMICs. ${ }^{89}$ Thus, the ethical challenge is to balance the goals of protecting research participants and reaping the benefits of appropriate clinical research. ${ }^{10}$ This paper explores Chile's recent experience to address this issue and develops ethical guidance for policy-makers. While especially useful for policy-makers in LMICs, our proposed ethical framework can also guide policy-makers in HICs who seek to protect participants while promoting beneficial research.

\section{EMERGING ECONOMIES AND RESEARCH REGULATION: THE CASE OF CHILE}

Clinical trials have expanded most rapidly in 'emerging economies', where appropriate healthcare infrastructure and skilled research 
Table 1 Comparison of the WMA's Declaration of Helsinki, ${ }^{59}$ the CIOMS's International Ethical Guidelines for Health-related Research Involving Humans ${ }^{21}$ and Chile's Law $20.850^{16}$

$\begin{array}{lll}\text { WMA, Declaration of Helsinki } & \begin{array}{l}\text { CIOMS, International Ethical Guidelines for Health- } \\ \text { (2013) }\end{array} & \begin{array}{l}\text { Chile's Law 20.850 } \\ \text { (2015) }\end{array}\end{array}$

Compensation for research-related injuries

\section{Article 15}

'Appropriate compensation and treatment for subjects who are harmed as a result of participating in research must be ensured'.

\section{Guideline 14}

'Sponsors and researchers must ensure that research participants who suffer physical, psychological or social harm as a result of participating in health-related research receive free treatment and rehabilitation for such harms, as well as compensation for lost wages, as appropriate. Such treatment and compensation are owed to research participants who are harmed physically, psychologically or socially, as a consequence of interventions performed solely to accomplish the purposes of research, regardless of fault'.

\section{Article $111 \mathrm{E}$}

The sponsor 'will be liable for injuries caused by the study, even when they result from facts or circumstances that could not have been foreseen or avoided according to the technical and scientific knowledge available at the time the injuries were produced. Moreover, once the injury is confirmed, it will be presumed that it was produced by the study. The opportunity to prosecute the responsible will expire ten years after the injury manifests'.

Article $111 \mathrm{~F}$

Sponsors 'will be obliged to have civil liability insurance, in accordance with the regulations dictated by the Ministry of Health...'.

\begin{tabular}{|c|c|}
\hline \multicolumn{2}{|l|}{ Post-trial access to treatments } \\
\hline $\begin{array}{l}\text { Article } 34 \\
\text { 'In advance of a clinical trial, } \\
\text { sponsors, researchers and host } \\
\text { country governments should } \\
\text { make provisions for post-trial } \\
\text { access for all participants } \\
\text { who still need an intervention } \\
\text { identified as beneficial in the } \\
\text { trial'. }\end{array}$ & $\begin{array}{l}\text { Guideline } 6 \\
\text { 'When participants' health needs during and after research } \\
\text { cannot be met by the local health infrastructure or the } \\
\text { participant's pre-existing health insurance, the researcher } \\
\text { and sponsor must make prior arrangements for adequate } \\
\text { care for participants with local health authorities, members } \\
\text { of the communities from which persons are drawn, or } \\
\text { nongovernmental organizations such as health advocacy } \\
\text { groups ... When access is provided after the research } \\
\text { to investigational interventions that have demonstrated } \\
\text { significant benefit, the provision may end as soon as the } \\
\text { study intervention is made available through the local } \\
\text { public health-care system or after a predetermined period } \\
\text { of time that the sponsors, researchers and community } \\
\text { members have agreed before the start of a trial'. }\end{array}$ \\
\hline
\end{tabular}

Excerpts from Law 20.850 have been translated by BA. To date, there are no procedural rulings on Law 20.850 that could provide further context for its interpretation.

CIOMS, Council for International Organizations of Medical Sciences; WMA, World Medical Association.

workforces attract private sponsors. ${ }^{11-13}$ As an emerging economy with a high density of externally sponsored clinical trials, ${ }^{14}$ Chile helpfully illustrates how countries in the current landscape of international research face ethical trade-offs in clinical trial regulation.

Chile passed its first law on clinical research in 2006. Criticised for insufficiently focusing on 'the protection of persons', ${ }^{15}$ this law has been succeeded by further research regulations. In 2015, Law 20.850 introduced changes regarding compensation for research-related injuries and post-trial access to treatments that are remarkably stringent. ${ }^{16}$ As in other Latin American countries, the regulations are more stringent than international guidelines (table 1), indicating a regional trend towards greater protections for research participants. ${ }^{17}$

\section{STRICTER PROTECTIONS, FEWER TRIALS?}

Several Chilean parliament members and academics raised concerns that Law 20.850 might disincentivise clinical research. ${ }^{18}$ Data from the Chilean Institute of Public Health, obtained through freedom of information requests, seem to support these concerns. Based on the Institute's mandatory registry of clinical trials involving investigational drugs, we found that the mean number of trials registered per year dropped from 95.5 (SD 6.9) before Law 20.850 was enacted to 75.8 (SD 6.2) (figure 1). The decline occurred mainly in phase $3 / 4$ clinical trials, which decreased from an average of 71.2 (SD 2.9) between 2010 and 2015 to 53 (SD 6.9) between 2016 and 2019. Clinical trial sponsorship remained stable during both time periods, with a mean of $97 \%$ trials per year sponsored by pharmaceutical companies from outside Chile.

Can the new regulatory protections for participants explain this decline in international clinical research? This is a difficult question, as the absolute number of trials in Chile is low and our observation period is relatively short. Nonetheless, several considerations support a causal relationship.

The decrease in clinical trial numbers immediately followed the introduction of Law 20.850, with new trial registrations remaining below 87 annually, the lowest 


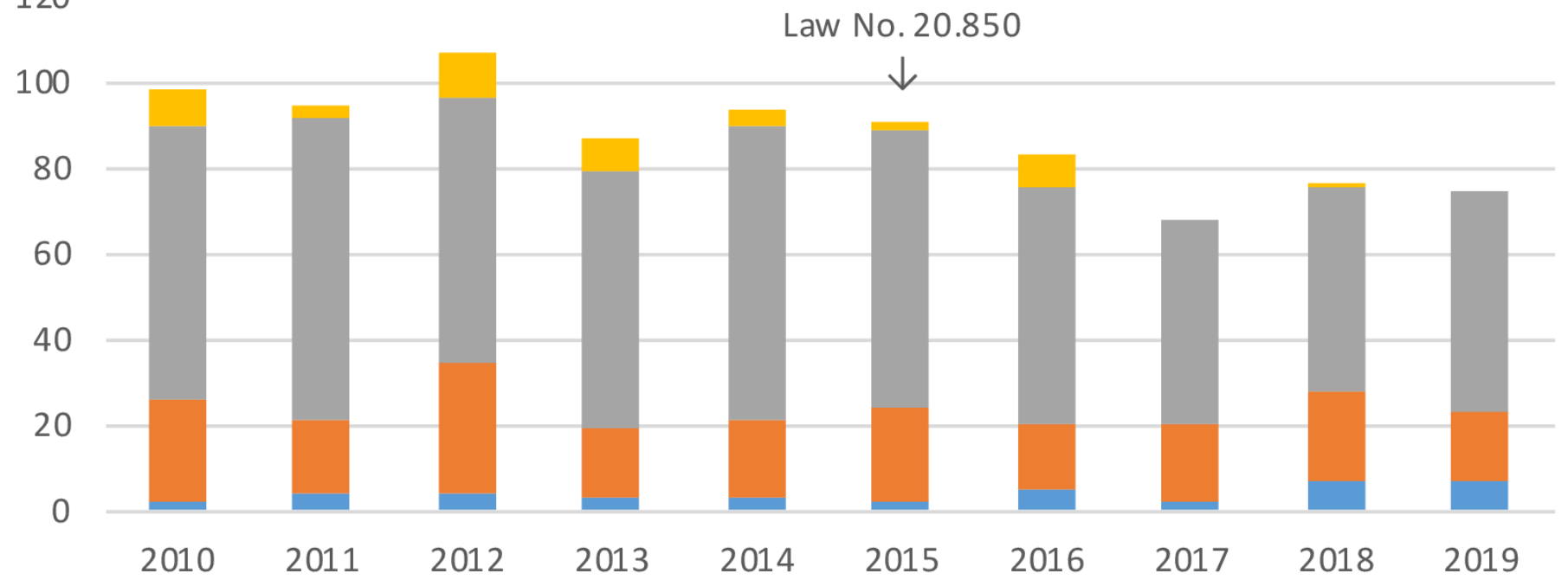

Phase 1 Phase 2 Phase 3 Phase 4

Figure 1 Number and phase of clinical trials registered in Chile between 2010 and 2019. Research sponsors are legally required to register all trials of drugs that have not been licensed by the Chilean Institute of Public Health (equivalent to the Food and Drug Administration in the USA) or are used outside their licensed indication. The arrow indicates when Chile's Law 20.850 was enacted. The total number of trials (2010-2019) was $N=876$. Three trials $(n=2(2011), n=1$ (2017)) were excluded since they were not reported as corresponding to phases 1-4. Data were obtained by freedom of information requests.

number of registrations observed in any of the previous years (figure 1). The sharpest decline has occurred in phase $3 / 4$ clinical trials, for which the new regulatory protections are most relevant. Phase $3 / 4$ trials can involve large numbers of participants, increasing the likelihood that sponsors must compensate for injuries. Study drugs are also more likely to prove beneficial in later trial phases, triggering post-trial access requirements. The increased prospect of substantial additional costs might have led sponsors to discontinue trials or move them to countries with less stringent regulatory protections, as occurred in India. ${ }^{10}$ Finally, other factors do not seem to explain the decline in clinical trial registrations in Chile. There was neither a wider downward trend in clinical research activity (indeed, global trial numbers have grown steadily in recent years ${ }^{19}$ ) nor wider economic or political instability in Chile that could have deterred research sponsors, and the Chilean clinical trial market is not yet considered saturated..$^{20}$

\section{ETHICAL TRADE-OFFS BETWEEN PROTECTING PARTICIPANTS AND REAPING RESEARCH BENEFITS}

Most laws and regulations have some negative consequences. In the present case, Law 20.850 might have disincentivised international research sponsors from registering new clinical trials in Chile. We recommend that policy-makers balance the goals of protecting research participants and reaping the benefits of appropriate clinical research using the following three-step framework (table 2). Using Law 20.850 as an example (table 1), we discuss how policy-makers should evaluate the need to revise existing protections.

\section{Step 1: do the regulatory protections have a sound ethical rationale?}

Policy-makers should determine, first, whether the regulatory protections are prima facie ethically defensible. Are the protections consistent with widely accepted ethical standards for clinical research? Do they protect participants' rights and interests, such as the right to be free of non-consensual experimentation or the interest in maintaining good health? Do the protections meet other ethical criteria, such as a just and fair distribution of research benefits and burdens?

A negative answer to all these questions provides a strong indication that the protections should be revised or revoked. For example, if a regulation excluded illiterate populations from research because of concerns about their decisional capacity, it should be revised. Because literacy is not necessary for making voluntary and informed decisions, excluding these populations prevents them from exercising their rights and, in some trials, promoting their interests by enrolling in potentially beneficial research. A blanket exclusion would also undermine principles of fair participant selection and conflict with recognised international guidelines. ${ }^{21}$ However, even in prima facie clear-cut cases, policymakers should engage in an in-depth ethical analysis using our proposed framework. Such analysis can help to decide whether and how a given regulation should be revised, all things considered.

In the present case, the provision of compensation for research-related injuries and post-trial access to proven beneficial treatments are generally consistent with sound ethical standards. However, a careful analysis of Law 20.850 
Table 2 A three-step ethical framework for evaluating existing regulatory protections for clinical research

\section{Guiding questions Concrete tasks}

1. Do the regulatory protections have Determine whether the regulatory protections are prima facie ethically defensible.

a sound ethical rationale?

Specifically, consider whether the protections are consistent with widely accepted ethical standards for clinical research; whether they protect participants' rights and interests; and whether the protections meet other ethical criteria, such as a just and fair distribution of research benefits and burdens.

A negative answer to all these questions provides a strong indication that the protections should be revised or revoked. However, the next steps of the framework should still be followed in order to confirm this answer and decide whether and how the protections should be revised, all things considered.

2. What are the benefits and costs of implementing the regulatory protections?

Survey all the relevant facts regarding the effects of implementing the regulatory protections.

Specifically, examine systematically who benefits from the protections and who incurs costs, including how significant the benefits and costs are. Have the affected people fared better or worse after the protections were introduced, as compared with how they would have fared if the protections had not been introduced?

Be sure to consider the benefits and costs for everyone affected, based on the list provided below. (Note that listed potential benefits can turn into potential costs when a given regulatory protection leads to a decline in clinical research activity and, consequently, to forgone benefits; conversely, listed potential costs can turn into potential benefits.)

Research Potential clinical benefits from the research intervention (during and after the trial participants if post-trial access to proven beneficial interventions is provided)

Potential clinical benefits from improved clinical care as part of the research ('inclusion benefits')

Potential clinical benefits from ancillary care (eg, following up on diagnoses based on research tests, treating conditions unrelated to the study's aims)

Potential clinical costs or harms (eg, research-related injuries)

Potential psychological benefits (eg, feelings of altruism)

Potential psychological costs (eg, anxiety from undergoing research procedures or receiving research results)

Potential social benefits (eg, social recognition)

Potential social costs (eg, stigma or discrimination)

Potential financial benefits from monetary compensation

Potential financial costs (eg, transportation costs, lost wages, treatment costs for research-related injuries)

Patients Potential clinical benefits from access to new interventions

Potential clinical benefits from research-related improvements in the quality of routine clinical care

Potential clinical benefits from advances in scientific or medical knowledge that address local health needs or priorities (primarily fostered through local research capacity building)

Potential clinical costs or harms if qualified clinicians are diverted from routine clinical care to clinical research

Wider community Potential financial benefits from cost savings for healthcare payers (if research sponsors cover study treatments)

Potential financial benefits from research-related economic activity (eg, researchrelated jobs or bonuses) and tax revenues

\section{Are the regulatory protections} justified, all things considered?

\section{Consider whether the regulatory protections are, all things considered, ethically justified.}

Specifically, weigh the benefits against the costs of the regulatory protections, consider to what extent the distribution of benefits and costs across different population groups promotes or curtails justice, and judge whether the costs to individuals or certain groups amount to a violation of their rights.

If the benefits of the regulatory protections do not outweigh the costs, the protections create new injustices or exacerbate existing ones, or the protections violate the rights of individuals or certain groups, there is reason to revise or amend the protections.

If none of these ethical problems is evident and the protections' benefits seem to outweigh the costs, then the regulatory protections are ethically justified.

Online supplementary appendix 1 provides a summary of how the framework can be applied to the Chilean Law 20.850. Online supplementary appendix 2 provides a slightly modified version of the framework for evaluating new regulatory protections under consideration (rather than existing regulatory protections). 
suggests that reasonable people would likely disagree about how the law should spell out these standards.

Law 20.850 requires research sponsors to obtain insurance that compensates for research-related injuries, 'even when they result from facts or circumstances that could not have been foreseen or avoided according to the technical and scientific knowledge available at the time'. ${ }^{16}$ This 'no-fault' compensation scheme is widely considered ethically sound because it protects participants by reducing the harms of research-related injuries and helps to distribute research risks and potential benefits fairly. ${ }^{22}$ However, Law 20.850 goes beyond 'no-fault' compensation by stipulating that 'once the injury is confirmed, it will be presumed that it was produced by the study'. ${ }^{16}$ The law only specifies that 'the opportunity to prosecute ... will expire ten years after the injury manifests', leaving open the possibility of prosecuting injuries that manifest at any point after a study. ${ }^{16}$ These provisions arguably place an excessive burden on research sponsors, as they might be held liable for conditions that arise unrelated to the research.

Law 20.850 also mandates that sponsors provide participants the investigational treatment-or, at a later point, the licensed drug - 'free of charge and for as long as its therapeutic utility remains' after the study has ended. ${ }^{16}$ These provisions are prima facie sound insofar as they protect the interests of patients and compensate for their participation in research. However, reasonable people might disagree as to whether the sole responsibility for providing post-trial access to treatments should be placed on sponsors. For example, when local authorities or institutions can contribute to ensuring post-trial access, the resulting burden on sponsors could reasonably be considered excessive. Moreover, it can be argued that the supply of effective treatments is sustainable only when sponsors and local actors actively engage in a collaborative partnership. ${ }^{23} 24$

In sum, while a prima facie case for Law 20.850 can be made, certain aspects of the protections it sets out can reasonably be considered to place excessive burdens on researchers and sponsors.

\section{Step 2: what are the benefits and costs of implementing the regulatory protections?}

After scrutinising the prima facie ethical case for the given regulatory protections, policy-makers should survey all the relevant facts regarding their effects. Specifically, policy-makers should examine systematically who benefits from the protections and who incurs costs, including how significant the benefits and costs are. We understand benefits and costs broadly: have the affected people fared better or worse after the protections were introduced, as compared with how they would have fared if the protections had not been enacted? This analysis should encompass everyone affected: not only research participants but also patients and the wider community who can receive benefits or incur costs from international clinical research (table 2).
We limit our discussion of Law 20.850 to the Chilean population, as this is the primary focus for Chilean policymakers and the law's global impact is less certain. However, depending on policy-makers' needs, our framework can be applied on a national, regional, or global level.

\section{Research participants}

Although participants are the intended beneficiaries of Law 20.850, we are unaware of empirical data demonstrating that more participants have received appropriate compensation for research-related injuries or post-trial access to beneficial interventions. However, even assuming good-faith implementation of the law, it is unlikely that it made participants substantially better off than they otherwise would have been. Previous regulations already had a 'no fault' scheme of compensation for research-related injuries (though less stringent), ${ }^{25}$ and post-trial access to investigational drugs was authorised (though not required). ${ }^{26}$ Since no more than twothirds of investigational drugs prove beneficial even in late-phase trials, ${ }^{27}$ this suggests that the law's benefits to research participants are limited.

Potential research participants might be worse off if the decline in clinical trials following Law 20.850 deprived them from the benefits of enrolment. Yet evidence suggests that clinical outcomes are neither better nor worse in clinical trials than in routine care. ${ }^{28}$ Moreover, the Chilean healthcare system provides meaningful access to health services, ${ }^{29}$ so that potential participants' clinical needs can reasonably be met outside the research context. And the financial compensation that potential participants might obtain by enrolling in research is typically small and limited to reimbursements for time or expenses incurred-particularly in phase $3 / 4$ trials, ${ }^{30}$ which declined most sharply after Law 20.850 was introduced. Thus, it seems unlikely that the law made potential participants noticeably worse-off.

Conversely, potential participants might be better off if the decline in trials meant they incurred fewer researchrelated risks. While robust evidence on the psychological and social risks of participating in research is lacking, the risk of serious health-related harm is generally low in late-phase clinical trials. ${ }^{31}$ Taken together, this suggests that Law 20.850 has led to limited benefits for clinical trial participants. Additionally, the law has likely had no noticeable impact on potential participants who have been deprived of the opportunity to enrol in research.

\section{Patients}

Due to the decline in clinical trials following Law 20.850, patients might be worse off due to a reduced access to successful products. However, these costs to patients are likely limited. New drugs can be licensed in Chile whether or not they have undergone local testing. ${ }^{32}$ Moreover, even if local data were required for licensure, the research currently being conducted does not address patients' most pressing health needs. According to our data, at most $13.5 \%$ of the trials registered in Chile between 2016 and 2019 addressed one of the top 
Table 3 Top 10 causes of death and disability combined in Chile, ${ }^{33}$ matched with the number and percentage of clinical trials that address the given cause between 2016 and 2019 (ie, after Law 20.850 was introduced)

\begin{tabular}{ll}
\hline $\begin{array}{l}\text { Top } 10 \text { causes of death and } \\
\text { disability combined }\end{array}$ & $\begin{array}{l}\text { Number of clinical trials } \\
\text { addressing the given cause }\end{array}$ \\
\hline (Chile, 2017) & $\begin{array}{l}\text { (Chile, 2016-2019; } \mathrm{n} \text { (\% of } 303 \\
\text { registered trials)) }\end{array}$ \\
\hline 1. Low back pain & $9(3)$ \\
2. Ischaemic heart disease & $9(3)$ \\
\hline 3. Stroke & $3(1)$ \\
4. Diabetes & $7(2.3)$ \\
5. Cirrhosis & $3(1)$ \\
6. Neonatal disorders & $9(3)$ \\
7. Depressive disorders & $1(0.3)$ \\
8. Headache disorders & 0 \\
9. Road injuries & 0 \\
10. Anxiety disorders & 0 \\
\hline Total & $41(13.5)$ \\
\hline
\end{tabular}

We used a broad interpretation of when trials address a given cause of death and disability, meaning the trial could address the given cause either directly or indirectly.

10 causes of disability-adjusted life years in the country ${ }^{33}$ (table 3). Moreover, around $30 \%$ of investigational drugs that undergo pivotal trials in Latin America are not licensed in the countries where they are tested, and licensed products remain unaffordable for most of the local population. ${ }^{34}$

Further, with a decline in clinical trial numbers, fewer patients might benefit from the improvements in clinical care that result from the organisational culture, systems and expertise fostered by research. ${ }^{35}$ However, in Chile, the associated costs are likely limited. Evidence about researchrelated improvements in clinical care comes mostly from HICs, which may be better equipped to implement quality improvements. ${ }^{36}$ Moreover, many reports of researchrelated clinical capacity building involve publicly funded trials. ${ }^{37}$ It is unclear to what extent private sponsors-which fund $97 \%$ of clinical trials in Chile-achieve similar results. Likewise, the decline in clinical trial numbers likely had no noticeable benefits for patients from research staff moving to provide routine clinical care, as Chile has no shortage of trained clinicans. ${ }^{38}$

Finally, patients might be worse off due to the decline in clinical trials and the resulting loss in research capacity building for the development of locally relevant drugs. Yet, only $2.5 \%$ of publications from externally sponsored trials in Chile list a local researcher as a coauthor, suggesting that local research involvement is limited. ${ }^{39}$ Moreover, according to our data, more than $70 \%$ of clinical trials in Chile are phase 3/4 trials. Because these trials test existing hypotheses, rather than generating new ones, they provide local researchers limited opportunities for developing their research skills. ${ }^{40}$ Indeed, Chilean researchers worry that local 'efforts for building a scientific and entrepreneurial development in Chile would ... be wiped out' because the requirements of Law 20.850 are too difficult for local researchers and sponsors to meet. ${ }^{41}$

In sum, the decline in clinical trials after Law 20.850 was introduced does not seem to have led to major costs or harms for patients.

\section{Wider population}

The wider population might be worse off economically if Law 20.850 deprived them of clinical trial activity and the associated financial and economic benefits. Privately sponsored trials can provide drugs and services free of charge and thereby save costs for healthcare payers. ${ }^{42} 43$ While there is no corresponding evidence from Chile, we expect some such cost savings to occur. According to some reports from HICs, clinical research activities also significantly boost the national economy. ${ }^{44}$ In Chile, pharmaceutical industry sources claim that private investment is 'annually around US\$30 million in clinical studies and provides jobs to more than 2100 Chilean professionals and technicians'. ${ }^{46}$ Moreover, local healthcare professionals might receive compensation from pharmaceutical companies for recruiting participants. ${ }^{47}$ Law 20.850 therefore likely led to noticeable economic costs for the wider population. However, considering a labour force of $>9$ million people and a GDP of $>\$ 277$ billion, ${ }^{48}$ these costs seem relatively small on a national scale.

\section{Step 3: are the regulatory protections ethically justified, all things considered?}

In the final step of our proposed framework, policymakers should consider whether the given regulatory protections are, all things considered, ethically justified. While step 2 mostly involves descriptive fact-finding, step 3 involves ethical judgement in light of the relevant facts. Specifically, policy-makers should weigh the benefits of the given protections against the costs. They should then consider how these benefits and costs are distributed across different population groups, and to what extent that distribution creates new injustices or exacerbates existing ones-for example, by worsening the lot of the least advantaged in society. ${ }^{49}$ Finally, policy-makers should judge whether the costs to individuals or certain groups amount to a violation of their rights or vital moral safeguards, such as the right not to be exposed to risks and burdens that are disproportionate to the potential benefits of the research. ${ }^{50-55}$

If the benefits do not outweigh the costs, the protections create new injustices or exacerbate existing ones, or the protections violate the rights of individuals or certain groups, there is reason to revise or amend the protections. If, however, none of these ethical problems is evident and the protections' benefits seem to outweigh the costs, then the protections are ethically justified. Table 4 provides examples of rights and justice considerations that are relevant for making these judgements. However, because rights and justice considerations are highly context-specific, policy-makers should carefully 
Table 4 Examples of rights and justice considerations when evaluating regulatory protections for clinical research

Rights considerations
Right to have one's interests
and well-being prevail over
the sole interest of society or
science

Right to be free from nonconsensual experimentation

\section{Application in the context of clinical research}

Right to have the risks and burdens of research participation minimised and not to be deprived of medically necessary procedures

Right not to be exposed to risk and burdens that are disproportionate to the potential benefits of the research; if the research does not have the potential to benefit one's health, it must entail no more than acceptable risk and acceptable burden

Right to be enrolled in research only when it is carried out under the supervision of a clinical professional who possesses the necessary qualifications and experience

For persons not able to provide consent: right to be enrolled in research only when it has the potential to produce real and direct health benefits, or when it entails minimal risk or burden, and the research has the aim of benefiting other persons in the same age or disease category

Right to be enrolled in research only with one's explicit free and informed consent to research

Right to withdraw from research freely at any time and for any reason without disadvantage or prejudice

For persons not able to provide consent: right to be enrolled in research only with the authorisation of a legal representative, to have one's previously expressed wishes relating to research taken into account, and to be involved to the greatest extent possible in the decision-making process; research should be undertaken only if the person concerned does not object

Right to non-discrimination and Right to have one's integrity, other rights and fundamental freedoms with regard to research respected non-stigmatisation without discrimination or stigmatisation on any grounds (eg, without distinction of race, religion, political belief, sexual orientation, economic or social condition)

Right to have any personal information collected treated confidentially

$\begin{array}{ll}\begin{array}{ll}\text { Right to know about any } \\ \text { information collected }\end{array} & \text { Right to know about any information collected about one's health } \\ & \text { Right to access other personal information collected } \\ & \text { Right to have one's wish not to be informed respected }\end{array}$

Right to receive research results Right to receive the conclusions of the research on request

Right to receive information relevant to one's current or future health or quality of life, within a framework of healthcare or counselling

Right to receive compensation Right to fair compensation for harm suffered as a result of participation in research for harm

Right to independent ethics review

Right to be enrolled in research only after independent examination by an ethics committee has confirmed that the dignity, rights, safety and well-being of research participants are protected

\begin{tabular}{ll}
$\begin{array}{l}\text { Right to enjoy the benefits of } \\
\text { scientific progress }\end{array}$ & $\begin{array}{l}\text { Right to access the benefits of science and its applications, including scientific knowledge } \\
\text { Right to have opportunities to contribute to the scientific enterprise and the freedom indispensable for } \\
\text { scientific research (eg, freedom from political and other interference) } \\
\text { Right to participate in science-related decision-making }\end{array}$ \\
\hline Justice considerations & $\begin{array}{l}\text { Application in the context of clinical research } \\
\text { Equal moral standing }\end{array}$ \\
$\begin{array}{l}\text { The dignity and rights of all research participants are to be respected so that all participants are treated } \\
\text { justly and fairly }\end{array}$ \\
Priority to the worst off* & $\begin{array}{l}\text { Special weight should be given to enhancing research benefits, and reducing research costs, to those who } \\
\text { are least advantaged }\end{array}$
\end{tabular}

The examples are derived from key international documents regarding human rights and health ${ }^{50-55}$ and relevant literature on health justice. ${ }^{49}$ Note that the referenced documents do not include a right to post-trial access, although this could potentially be derived from other rights listed in the table (eg, the right to receive research results and the right to enjoy the benefits of scientific progress).

*A 'moderate prioritarian' view - which gives substantial, but not absolute priority to the worst off-is widely endorsed because it can be justified drawing on egalitarian, prioritarian, sufficientarian and utilitarian theories of distributive justice. ${ }^{49}$

(and critically) consider the given legal, political and social contexts.

All things considered, our analysis suggests that the decline in clinical trials after Law 20.850 was introduced likely resulted in limited benefits to research participants and limited costs to patients, but noticeable costs to the wider population (online supplementary appendix 1). These findings support the common idea that LMICs can be made worse off by regulatory protections that disincentivise international clinical research, but with four important qualifications. First, since we did not conduct a formal cost-benefit analysis, our findings remain tentative. Second, both benefits and costs appear to be relatively small and might not be significant overall. This could be different in other countries, especially those with higher trial numbers. Third, in an emerging economy like Chile, costs resulting from fewer clinical trials seem to be mainly due to economic losses, instead of forgone benefits to participants and patients. Again, this could be different in other contexts, for example, 
resource-poorer LMICs where trials might help to meet basic health needs. Finally, both the benefits and costs of Law 20.850 could change over time. For example, clinical trial numbers might recover as sponsors adapt to the law, raising the question whether the limited aggregate costs during an expected transition period are a "price worth paying' for the additional protections for participants.

Our findings also highlight the important fact that the benefits and costs of research regulations can be of multiple kinds and degrees, and that they are distributed across different populations. This brings out considerations of rights and justice. Partly because the benefits and costs of Law 20.850 are relatively small, our analysis does not suggest that it led to injustices or rights violations. However, where protections have more important benefits and costs, policy-makers should evaluate their distribution and moral significance by drawing on relevant notions of justice and rights.

Finally, our analysis raises concerns about how international clinical research in Chile is currently being conducted. Specifically, the costs of implementing Law 20.850 are limited mainly because the decline in clinical trials does not entail significant losses in research capacity building and research that is responsive to local health needs. This is cause for concern, given the potential of local research capacity to improve health and reduce health disparities in Chile. ${ }^{56}$

In sum, we believe that building a strong ethical case for revising Law 20.850 remains elusive. However, dispensing with those aspects of the law that can be reasonably considered too burdensome, while upholding appropriate protections regarding research-related injuries and post-trial access, might help to remove disincentives for conducting international clinical research in Chile. Any regulatory changes in this direction should ideally be associated with measures to actively promote local research capacity building and the conduct of research that is responsive to local health needs. For this to happen, Chilean policy-makers might strengthen research institutions, set clear research priorities, provide adequate research funding, and promote innovative partnerships with research sponsors. ${ }^{57}$

\section{CONCLUSION}

Policy-makers should be aware of the ethical trade-offs involved in regulating clinical research. We have proposed a three-step ethical framework for balancing the goals of protecting research participants and reaping the benefits of hosting clinical trials. This framework guides policymakers in integrating key ethical and practical considerations, including which population groups are affected by a given set of regulatory protections, how different types of benefits and costs are distributed across these groups, and whether the rights of individuals or groups are being violated. Our framework could helpfully be expanded, for example, by further specifying notions of justice and rights, or incorporating elements of more formal costbenefit analysis. ${ }^{58}$ However, policy-makers often have to make decisions with limited information and under time constraints. In this context, our framework provides useful ethical insights, which policy-makers might need to weigh with political or other considerations. Of note, although we use Chile as an illustrative example, our framework applies in LMICs as well as HICs and can be used to evaluate the need to revise existing protections with a national, regional or global scope. Similarly, the framework can be adapted so that policy-makers can evaluate new protections under consideration (online supplementary appendix 2).

Twitter Bernardo Aguilera @bedobardo and Annette Rid @anetrid

Acknowledgements Thanks to Benjamin Berkman, Alberto Lecaros, Joseph Millum, Christina Roadevin, Sofía Salas, Rodrigo Salinas and three anonymous reviewers for their help and comments during the preparation of this paper.

Contributors BA and AR conceived the idea for the paper. BA acquired and analysed the data and wrote the first draft. AR and DDG revised the paper critically for important intellectual content. All authors approved of the final version and agreed to be accountable for all aspects of the work.

Funding This work was supported by the Clinical Center Department of Bioethics, which is in the Intramural Program of the National Institutes of Health.

Disclaimer The views expressed here are those of the authors and do not necessarily reflect the policies of the National Institutes of Health or the U.S Department of Health and Human Services.

Competing interests None declared.

Patient consent for publication Not required.

Provenance and peer review Not commissioned; externally peer reviewed.

Data availability statement The datasets analyzed during the current study are available from the authors on reasonable request.

Open access This is an open access article distributed in accordance with the Creative Commons Attribution 4.0 Unported (CC BY 4.0) license, which permits others to copy, redistribute, remix, transform and build upon this work for any purpose, provided the original work is properly cited, a link to the licence is given, and indication of whether changes were made. See: https://creativecommons.org/ licenses/by/4.0/.

\section{ORCID iDs}

Bernardo Aguilera http://orcid.org/0000-0001-9138-5003

Annette Rid http://orcid.org/0000-0003-1117-1975

\section{REFERENCES}

1 Drain PK, Robine M, Holmes KK, et al. Trial watch: global migration of clinical trials. Nat Rev Drug Discov 2014;13:166-7.

2 Normile D. The promise and pitfalls of clinical trials overseas. Science 2008;322:214-6.

3 MacMahon S, Perkovic V, Patel A. Industry-Sponsored clinical trials in emerging markets: time to review the terms of engagement. JAMA 2013;310:907-8.

4 Plomer A. The law and ethics of medical research: international bioethics and human rights. London: Routledge-Cavendish, 2005: 113-35.

5 Pavone IR. Legal responses to placebo-controlled trials in developing countries. Global Bioethics 2016;27:76-90.

6 Shukla S. India's amended trials regulations spark research exodus. Lancet 2013;382:845.

7 Sugarman J, Bhan A, Bollinger R, et al. India's new policy to protect research participants. BMJ 2013;347:f4841.

8 Nuffield Council on Bioethics. The ethics of research related to healthcare in developing countries. London: NCB, 2002.

9 Participants in the 2001 Conference on Ethical Aspects of Research in Developing Countries. Ethics. Fair benefits for research in developing countries. Science 2002;298:2133-4.

10 Porter G. Regulating clinical trials in India: the economics of ethics. Dev World Bioeth 2018;18:365-74.

11 Thiers FA, Sinskey AJ, Berndt ER. Trends in the globalization of clinical trials. Nat Rev Drug Discov 2008;7:13-14. 
12 Petryna A. When experiments travel: clinical trials and the global search for human subjects. Princeton, NJ: Princeton University Press, 2009: 1-258.

13 Atal I, Trinquart L, Porcher R, et al. Differential globalization of Industry- and Non-Industry-Sponsored clinical trials. PLOS One 2015;10:e0145122.

14 Pugatch Consilium. The biopharmaceutical competitiveness \& investment (BCl) survey 2017, Latin America special report, 2017.

15 Sotomayor MA. Regulación de la investigación biomédica en Chile. Acta Bioethica 2008;14:79-89.

16 Law No. 20.850/2015 (Chile). Available: http://bcn.cl/1v7lo [Accessed 19 Nov 2019].

17 Saenz C, Heitman E, Luna F, et al. Twelve years of Fogarty-funded bioethics training in Latin America and the Caribbean: achievements and challenges. J Empir Res Hum Res Ethics 2014;9:80-91.

18 Legislative history of law No. 20.850/2015 (Chile). Available: https:// www.bcn.cl/historiadelaley/nc/historia-de-la-ley/4018/ [Accessed 19 Nov 2019].

19 Zwierzyna M, Davies M, Hingorani AD, et al. Clinical trial design and dissemination: comprehensive analysis of ClinicalTrials.gov and PubMed data since 2005. BMJ 2018;361:k2130.

20 Pharm-Olam International. Clinical trials in Latin America: a region of diversity, a world of opportunity, 2014. Available: https://www. pharm-olam.com/whitepapers

21 Council for International Organizations of Medical Sciences. International ethical guidelines for health-related research involving humans. Geneva, Switzerland: Council for International Organizations of Medical Sciences, 2016.

22 Henry LM, Larkin ME, Pike ER. Just compensation: a nofault proposal for research-related injuries. J Law Biosci 2015;2:Isv034-68.

23 Grady C. The challenge of assuring continued post-trial access to beneficial treatment. Yale J Health Policy Law Ethics 2005;5:425-35.

24 Lavery JV. Putting international research ethics guidelines to work for the benefit of developing countries. Yale $J$ Health Policy Law Ethics 2004;4:319-36.

25 Decree No. 30/2013 (Chile). Modifica Decreto $n^{\circ} 114$, de 2010, que aprueba Reglamento de la Ley No. 20.120. Available: http://bcn.cl/ $1 \times 5$ ae [Accessed 19 Nov 2019].

26 Exempt Resolution No. 403/2015 (Chile). Aprueba guía para la autorización y control del uso de productos farmacéuticos. Instituto de Salud Publica de Chile.

27 Hay M, Thomas DW, Craighead JL, et al. Clinical development success rates for investigational drugs. Nat Biotechnol 2014;32:40-51.

28 Vist GE, Bryant D, Somerville L, et al. Outcomes of patients who participate in randomized controlled trials compared to similar patients receiving similar interventions who do not participate. Cochrane Database Syst Rev 2008;3:MR000009.

29 Atun R, de Andrade LOM, Almeida G, et al. Health-system reform and universal health coverage in Latin America. Lancet 2015;385:1230-47.

30 Marathe PA, Tripathi RK, Shetty YC, et al. Payment for participation in clinical research: review of proposals submitted to the ethics committees. Perspect Clin Res 2018;9:64-9.

31 Berlin JA, Glasser SC, Ellenberg SS. Adverse event detection in drug development: recommendations and obligations beyond phase 3 . Am J Public Health 2008;98:1366-71.

32 Decree No. 3/2011 (Chile). Aprueba reglamento del sistema nacional de control de los productos farmacéuticos de uso humano. Available: http://bcn.cl/1uvxb [Accessed 19 Nov 2019].

33 The Institute for Health Metrics and Evaluation (IHME). Chile profile. Seattle, WA: IHME, University of Washington, 2018. http://www. healthdata.org/results/country-profiles

34 Homedes N, Ugalde A. Availability and affordability of new medicines in Latin American countries where pivotal clinical trials were conducted. Bull World Health Organ 2015;93:674-83.

35 Denburg A, Rodriguez-Galindo C, Joffe S. Clinical trials infrastructure as a quality improvement intervention in low- and middle-income countries. Am J Bioeth 2016;16:3-11.

36 Boaz A, Hanney S, Jones T, et al. Does the engagement of clinicians and organisations in research improve healthcare performance: a three-stage review. BMJ Open 2015;5:e009415.
37 Wilson PT, Giessler K, Morris MC. Impact of a clinical trial in two district hospitals in Ghana: perspectives of Ghanaian researchers. J Empir Res Hum Res Ethics 2018;13:486-93.

38 Ministry of Health of Chile. Informe sobre brechas de personal de salud por servicio de salud, 2017. Available: https://www.minsal.cl/ wp-content/uploads/2015/08/Informe-Brechas-RHS-en-Sector-P\% C3\%BAblico Abril2017.pdf

39 Hoekman J, Frenken K, de Zeeuw D, et al. The geographical distribution of leadership in globalized clinical trials. PLoS One 2012;7:e45984.

40 Haeussler C, Rake B. The changing geography of clinical research: a critical analysis of its drivers. Ind Corp Change 2017;26:285-310.

41 Khoury M, Figueroa FE. Magic realism: a Latin American paradigm for stem cell research \& development? Gene Ther 2020;27:2-5.

42 Liniker E, Harrison M, Weaver JMJ, et al. Treatment costs associated with interventional cancer clinical trials conducted at a single UK institution over 2 years (2009-2010). Br J Cancer 2013;109:2051-7.

43 Shen L-J, Chou H, Huang C-F, et al. Economic benefits of sponsored clinical trials on pharmaceutical expenditures at a medical center in Taiwan. Contemp Clin Trials 2011;32:485-91.

44 Partners TEConomy, PhRMA for. The economic impact of the US biopharmaceutical industry: national and state estimates. Columbus, OH: TEConomy Partners, 2017.

45 KPMG LLP. NIHR clinical research network: impact and value assessment. KPMG LLP, 2016.

46 Cámara de la Innovación Farmacéutica de Chile (CIF). Quiénes somos [Internet] Chile: CIF, 2017. Available: http://www.cifchile.cl/ camara-de-la-innovacion-farmaceutica-de-chile/ [Accessed 19 Nov 2019].

47 Bryant J, Powell J. Payment to healthcare professionals for patient recruitment to trials: a systematic review. BMJ 2005;331:1377-8.

48 Organisation for Economic Co-operation and Development (OECD). Chile: Country statistical profile 2018 [Internet] OECD, 2018. Available: https://data oecd.org/chile.htm [Accessed 19 Nov 2019].

49 Sharp D, Millum J. Prioritarianism for global health investments: identifying the worst off. J Appl Philos 2018;35:112-32.

50 Council of Europe. Convention for the protection of human rights and dignity of the human being with regard to the application of biology and medicine: convention on human rights and biomedicine, Oviedo, 1997. Available: https://www.coe.int/en/web/conventions/ full-list/-/conventions/treaty/164

51 United Nations. Committee on economic, social and cultura rights. Substantive issues arising in the implementation of the International covenant on economic, social and cultural rightsrights. Geneva, 2001. Available: https://digitallibrary.un.org/ record/442869? In=en

52 Council of Europe. Additional protocol to the convention on human rights and biomedicine, concerning biomedical research. Strasbourg, 2005. Available: https://www.coe.int/en/web/conventions/full-list/-/ conventions/treaty/195

53 UNESCO. Universal Declaration on bioethics and human rights. Paris, 2006. Available: http://unesdoc.unesco.org/images/0014/ 001461/146180E.pdf

54 UNESCO. The right to enjoy the benefits of scientific progress and its applications. Venice, 2009. Available: https://unesdoc.unesco. org/ark:/48223/pf0000185558

55 United Nations. Committee on economic, social and cultural rights. General Comment No. 25 on science and economic, social and cultural rights art. 15.1.b, 15, 2020. Available: https://www.ohchr.org/ en/hrbodies/cescr/pages/cescrindex.aspx

56 Franzen SRP, Chandler C, Lang T. Health research capacity development in low and middle income countries: reality or rhetoric? A systematic meta-narrative review of the qualitative literature. $B M J$ Open 2017;7:e012332.

57 Wolitz R, Emanuel E, Shah S. Rethinking the responsiveness requirement for international research. Lancet 2009;374:847-9.

58 Boardman AE, Greenberg DH, Vining AR, et al. Cost-Benefit analysis: concepts and practice. Fifth edition. New York: Cambridge University Press, 2018.

59 World Medical Association. Declaration of Helsinki. Ethical principles for medical research involving human subjects. 64th WMA General assembly, Fortaleza, Brazil, 2013. Available: https://apps.who.int/iris/ handle/10665/268312 